\title{
Autoappendektomie in der Antarktis
}

\author{
Der Wille zum Überleben in einer \\ ausweglos erscheinenden Situation \\ brachte einen russischen Chirurgen \\ dazu, ohne medizinisch qualifizier- \\ te Assistenz an sich selbst eine \\ Appendektomie durchzuführen.
}

- Am 5. November 1960 lief das Expe-

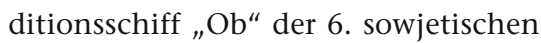
Antarktisexpedition aus dem Hafen von Leningrad aus und erreichte nach 36-tägiger Reise das Eisschelf der Prinzessin-Astrid-Küste. Nach neunwöchiger Arbeit wurde am 18. Februar 1961 die neue Forschungsstation Novolazarevskaya eröffnet, gerade noch vor Einbruch des Polarwinters mit monatelanger Dunkelheit, Schneestürmen und extremen Tieftemperaturen. Es war klar, dass das Schiff ein Jahr lang diesen Ort nicht würde verlassen können.

Unter den Expeditionsteilnehmern war der 27-jährige Leningrader Chirurg Leonid Ivanovich Rogozov, der an der Expedition als Arzt und als Meteorologe teilnahm. Am 29. April 1961 fühlte sich Rogozov krank und schwach, er litt unter Übelkeit und später unter Oberbauchschmerzen, die sich im Lauf des Tages in den rechten unteren Quadranten des Abdomen verlagerten. Seine Körpertemperatur stieg auf $37,5^{\circ} \mathrm{C}$ und er notierte im Tagebuch: „Sieht aus, als ob ich eine Appendizitis hätte. Ich sage lieber noch nichts. Warum sollte ich meine Freunde beunruhigen? Wer könnte mir helfen?"

Rogozov wusste, dass er diesen Ort nicht würde verlassen können. Er wandte bei sich selbst alle verfügbaren konservativen Maßnahmen wie Antibiotika und lokale Kälteapplikationen an. Sein Zustand verschlechterte sich aber im Lauf des 30. April zusehends, die Körpertemperatur stieg und das Erbrechen nahm zu. Tagebucheintrag: „Es tut weh wie der Teufel! ... Es gibt nur einen Ausweg: ich muss mich selbst operieren ... Es erscheint fast unmöglich ... Aber ich kann nicht einfach daliegen und nichts tun."
Auf Anweisung von Rogozov wurde alles aus seinem Zimmer geräumt mit Ausnahme seines Bettes, zweier Tische und einer Lampe. Zwei Kollegen beleuchteten den Raum mit UV-Licht und sterilisierten das Bettuch und die Instrumente. Der Meteorologe Artemev, der Mechaniker Teplinsky und der Stationsdirektor Gerbovich waren als Assistenten ausersehen und wuschen sich die Hände wie Chirurgen. Für den Fall, dass er bewusstlos werden würde, gab Rogozov Anweisungen, welche Medikamente ihm injiziert werden sollten und wie sie die Atmung aufrechterhalten konnten.

Rogozov legte sich mit leicht angehobenem Oberkörper aufs Bett und legte sich ein Kissen unter die rechte Hüfte, damit der rechte Unterbauch leicht angehoben war. Nach lokaler Desinfektion des Operationsgebietes verabreichte er sich selbst eine Lokalanästhesie mit $20 \mathrm{ml} \mathrm{0,5 \%}$ Procain und führte 15 Min. später einen $12 \mathrm{~cm}$ langen Unterbauchschnitt durch. Wegen schlechter Sichtverhältnisse mussten die „Assistenten“ gelegentlich einen Spiegel halten, damit er besseren Einblick in das Operationsgebiet bekam. Wegen allgemeiner Schwäche und Schwindelerscheinungen musste er nach 30-40 Min. kurze Pausen einlegen. Dennoch gelang es ihm, die massiv aufgetriebene Appendix zu entfernen, eine dichte Naht zu setzen und das Peritoneum nach entsprechender Applikation von Antibiotika zu schließen. Die Gesamtdauer der Operation betrug 1 Stunde und 45 Min.

Am nächsten Tag war das Fieber zurückgegangen, er fühlte sich zwar immer noch schlecht, aber besser als am Tag zuvor. Am vierten postoperativen Tagen verschwanden die Zeichen der lokalisierten Peritonitis und am fünften Tag war die Körpertemperatur normal. Eine Woche postoperativ entfernte der Chirurg selbst die Fäden und nach zwei Wochen erledigte er seinen normalen Dienst. Am 8. Mai 1961 schrieb Rogozov im Tagebuch unter anderem: „Mit Schrecken stellte ich die dunkle Verfärbung der Appendix fest. Nur einen Tag länger und sie wäre perforiert ...".

Zwar gibt es in der Literatur einige Fallbereichte über Autoappendektomien, die erste davon 1921 von Dr. Kane, der allerdings chirurgische Assistenten zur Verfügung hatte. Rogozovs Selbstoperation ist wahrscheinlich der erste erfolgreiche Eingriff abseits jeglicher Zivilisation und ohne qualifizierte Assistenz. Er ist ein Zeugnis für Entschlossenheit und den absoluten Willen zum Überleben. Glorifizierungen dieser Art lagen Rogozov jedoch fern. Befragt nach der Bedeutung dieser Heldentat pflegte er zu antworten: „Ein Job wie jeder andere, ein Leben wie jedes andere."

H. S. FÜEßL =

\section{- V. Rogozov, N. Bermel \\ (v.rogozov@sheffield.ac.uk), Autoappendicec- tomy in the Antarctic, BMJ 339 (2009) 7735 , 1420-1422}

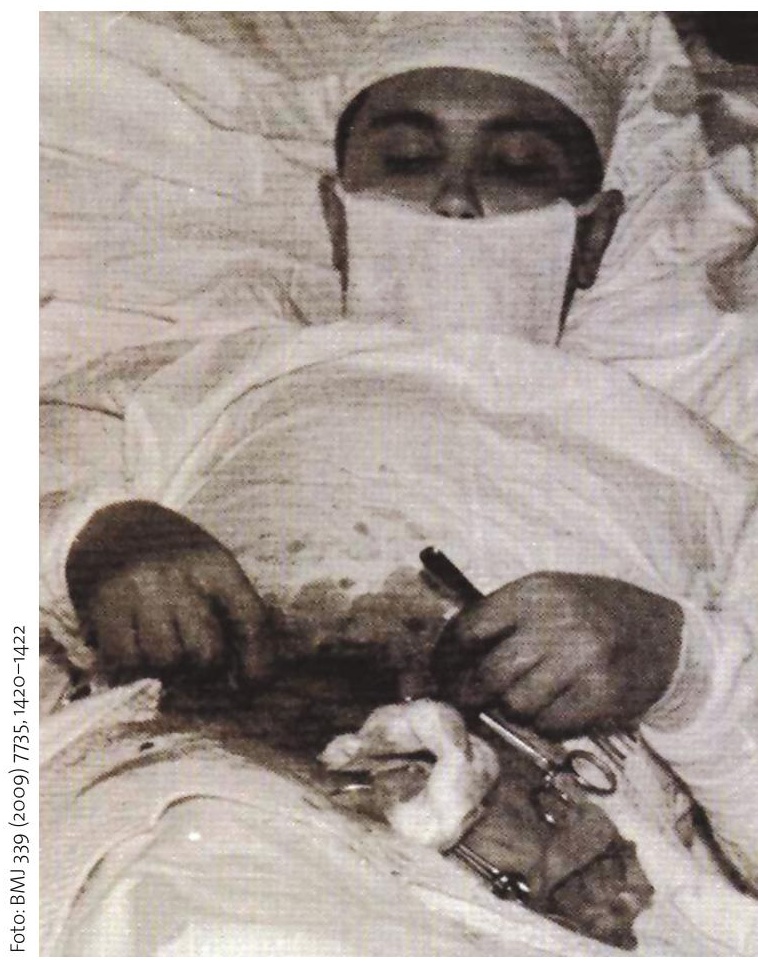

Leonid Ivanovich Rogozov appendektomiert sich selbst. 